ships leading to a $\mathrm{PhD}$ are down, applications for MSc courses, for which the council provides about 170 grants, are up by about $20 \%$.

The Science Research Council said this week that it is as yet too soon to be able to tell which subjects have been most affected, and the council could not even say whether applications for PhDs or for masters courses were hardest hit.

The Medical Research Council, which has just over 400 awards on offer, 320 for $\mathrm{PhDs}$ and just under 100 for masters' courses, has no such problems. A spokesman for the council said this week that applications were about the same as last year, although it looked as though a shortfall was likely earlier in the year. In fact over 1,000 applications were received.

What are the reasons for the fall in applications to SRC and NERC? Spokesmen for the councils are a little reluctant to speculate on the reasons for the reductions in applications except to point to the much improved job market for graduates this year, and to the publicity given over the past fow years to the difficulty $\mathrm{PhDs}$ were experiencing in finding jobs. The attack on the $\mathrm{PhD}$ launched by the Confederation of British Industry when giving evidence to a House of Commons Select Committee recently is just one of the pointers.

It is also possible that graduates are following the trends that can be discerned in schools and first degree courses away from physics and chemistry and towards medical and social science. A further factor may be the size of the grant, while there have also been suggestions that more graduates with good firsts are entering industry rather than moving into research with the result that the quality of applicants for PhDs is lower than last year. The MRC says its figures do not support this, and NERC is adamant that the candidates that are filling its research studentships are "fully acceptable". Whether the situation will be the same among the SRC's depleted ranks will not become plain until the council finally completes its sums later this year.

\section{HIGH ENERGY PHYSICS}

\section{Conventional CERN}

THREE months after the decision was taken to incorporate conventional magnets, rather than superconducting magnets, in the super proton synchrotron now being built at CERN, progress is continuing apace. A spokesman for the organization said this week that although the civil engineers who are engaged in building the tunnel have run into some difficulties, for example they encountered a pocket of natural gas which delayed progress earlier in the summer-there is at present no concern that a $400 \mathrm{GeV}$ beam will not be available by late 1976 .

There is little doubt that a ripple of disappointment ran through the high energy physics world with the announcement that no superconducting magnets will be incorporated in any phase of the design. But progress with superconducting accelerators around the world has been disappointing and the CERN council in June decided that the risks of non-conventional magnets would not be worthwhile. One of the problems with superconducting magnets of the size required for CERN is that there is no guarantee that every magnet manufactured will behave in exactly the same way.

A further problem is that confidence with superconducting accelerators is at a low ebb following the failure of physicists at Stanford University to obtain a sufficiently large voltage gradient in their superconducting linear electron accelerator. The problems at Stanford are the same as those that were being attacked at least thirty months ago. Essentially they boil down to the quality of the surface inside the accelerator sections, which determines the voltage gradient which each section can withstand.

But the decision at CERN to forego superconducting magnets means that the remaining deadlines in the programme are more likely to be met than otherwise would have been the case. And, of course, conventional magnets

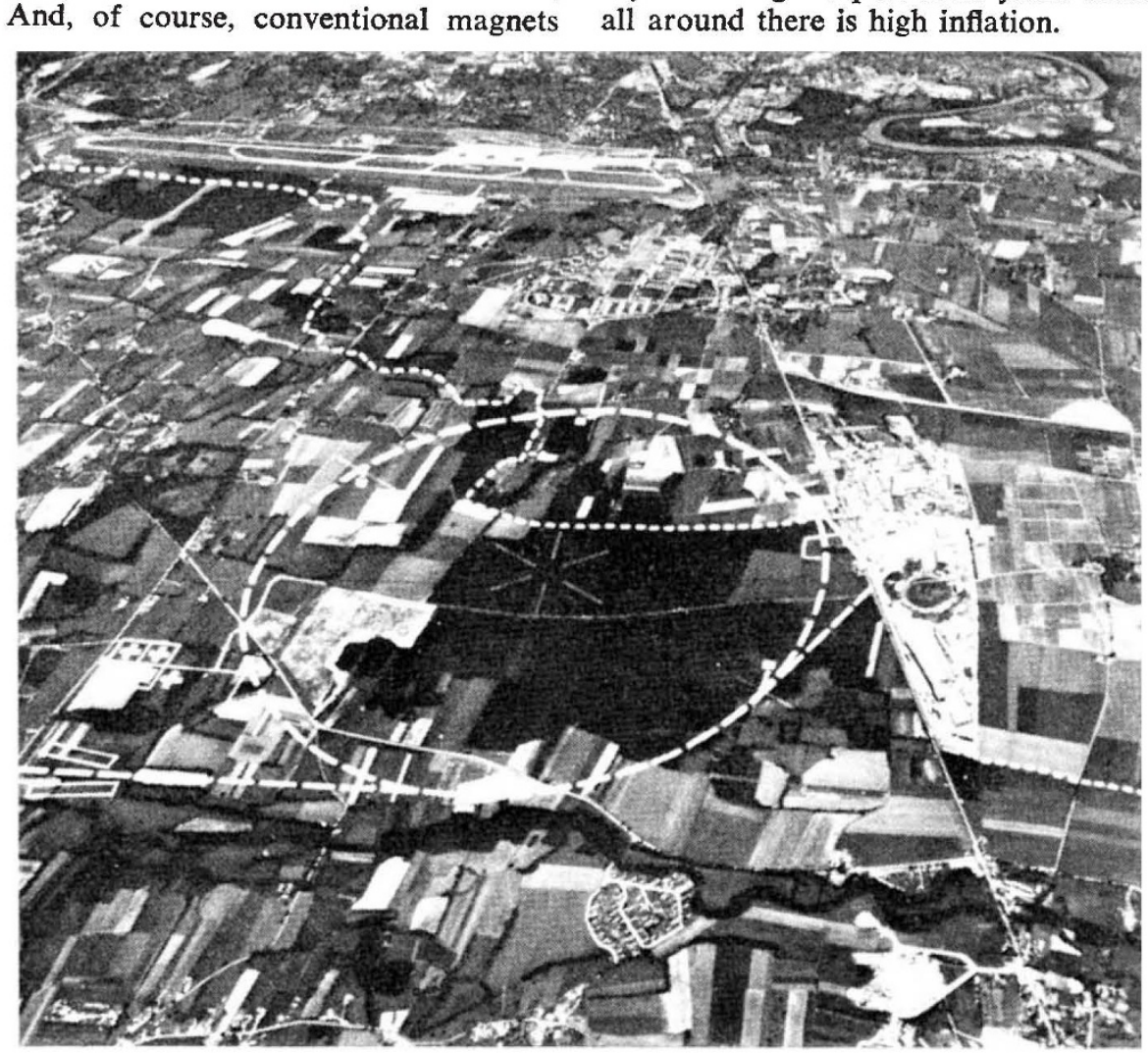

Aerial view of CERN and the outline of the super proton synchroton. The shorter dotted line is the Franco-Swiss frontier. imply that the costs will be lower.

Two kilometres of the 6.9 kilometre accelerator ring have already been completed and the plans are for the tunnelling work to be completed by the spring of 1975 , but the "mole" which is at present busily at work underground will have completed its work by the autumn of 1974. Installation of the magnets will, however, start in the completed sections of the tunnel in January 1974. All the components have now been ordered and some of the first magnets have already arrived on site. Two of the 32 Nord-10 computers which have been ordered for the accelerator have also been delivered.

Another decision taken in June means that the first beam out of the accelerator will be of $400 \mathrm{GeV}$ and there will not be an intermediate stage where $200 \mathrm{GeV}$ will be available. This is certainly an advance on a year ago when there was only a commitment to build a $200 \mathrm{GeV}$ accelerator and the extra magnets to increase the energy to $300 \mathrm{GeV}$ would only be included if "the physics interest makes the extra $100 \mathrm{GeV}$ important". Now it seems that $400 \mathrm{GeV}$ will be obtained without the project going outside its original budget. During 1973, the third year of the project, 188 million Swiss francs will be spent while it is estimated that the budget next year will be nearer SF200 million. It is a remarkable testimony to Dr J. B. Adams, the director general of the project, that costs in real terms have only increased by $6 \%$ a year during the past three years when all around there is high inflation. 